\title{
Strength and deformability of reinforced concrete elements under oblique eccentric short-term dynamic compression, tension and bending
}

\author{
Dmitriy Sarkisov ${ }^{1}$, Nikolay Gorlenko ${ }^{1, *}$, Gleb Gorynin ${ }^{2}$, Yuri Sarkisov ${ }^{1}$, Gafurzhan \\ Izmailov $^{3}$, and Tatyana Shepelenko ${ }^{1}$ \\ ${ }^{1}$ Tomsk State University of Architecture and Building, 2, Solyanaya ave., 634003, Tomsk, Russia \\ ${ }^{2}$ Surgut State University, 1, Lenina ave, 628403, Surgut, Russia \\ ${ }^{3}$ Tomsk State Pedagogical University, Kievskaya ave., 634061, Tomsk, Russia
}

\begin{abstract}
The paper deals with research data of reinforced concrete rectangular and I-shaped cross-section elements, operating under oblique eccentric short-term dynamic compression, tension and bending. The method of reinforced concrete elements calculation using the theory of surfaces of relative resistance regarding strength and crack resistance is suggested. It is based on the deformation model with the use of real nonlinear diagrams of concrete and reinforcement. This method makes it possible to observe strength and crack resistance of reinforced concrete elements sections in the entire range of loadings from the central tension to axial compression. Experimental investigation of symmetrically reinforced concrete elements on oblique eccentric short-term dynamic compression, tension and oblique bending was carried out. Effect of longitudinal force level on strain distribution through the depth of section, bearing capacity, the failure scheme and other parameters are estimated.
\end{abstract}

\section{Introduction}

The modern approach to engineering design requires development of design diagrams that comply with the spatial operation of bearing systems of buildings and structures. Numerical study on operation of industrial buildings frames under short-term dynamic loading has shown that significant moments, operating out of plane of frames, appear in the frame columns apart from the bending moments in the plane of frames. Thus, when operated as part of three-dimensional systems and with short-term dynamic loadings, the stress strain behavior of the reinforced concrete elements significantly changes that must be considered at the designing and evaluating of the bearing capacity of structures referred to several existing studies [1-10]. Especially it is characteristic for reinforced concrete columns of buildings frame and their joints.

Designing of reinforced concrete elements under the combined action of the longitudinal forces and bending moments of two planes is proposed to carry out using

\footnotetext{
*Corresponding author: gorlen52@mail.ru
} 
nonlinear deformation model as in Russian regulatory literature. The estimation is made by successive approximations method and it is proposed to make special computer programs for its realization. The regulatory literature shows only an approximate algorithm for making such programs, and their realization is not available to all of them, as specific knowledge is required not only in the professional field, but also in programming.

There are engineering approaches to the estimation of bearing capacity of the reinforced concrete elements under complex stress-strain states, based on the use of special curves that describe the strength of the element, both in Russian and foreign standards. These curves are usually plotted according to the specific dependences and represented in the regulatory literature in the form of bearing capacity graphs of elements at the fixed volumes of reinforcement. In addition, the Russian standards represent such graphs for the elements, experiencing oblique eccentric compression, oblique bending and its particular cases, and it is not possible to evaluate the strength of elements under oblique eccentric tension. Moreover, all of these graphs can be used only under static loading.

At present time it is possible to use specialized programs for the designing of structures and plotting of above mentioned bearing capacity graphs. The full range of graphs for possible combinations of longitudinal forces and bending moments of two planes is presented here, and the program forms an area or surface of resistance according to the strength. Developers have some problems at plotting these areas and surfaces, related to the limits of regulatory documents or irregularity of algorithm development. There are cases in practice when the surfaces are non-convex, have slits, surges and drops, which contradict the postulate of Drucker - Hill (Fig. 1). Thus occurred the necessity in developing the new method.

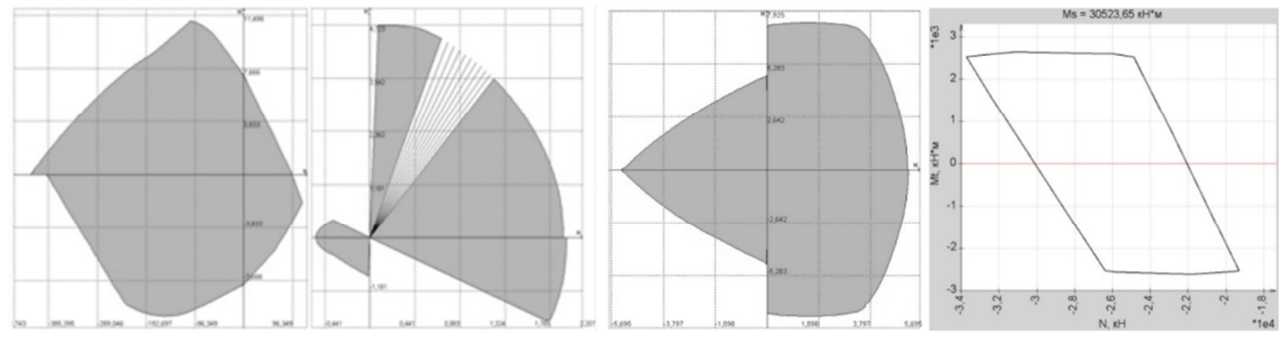

Fig. 1. Slits, drops and surges at plotting the surfaces and areas of resistance according to the strength of standard sections.

\section{Calculation method}

Taking into account these unsatisfactory features, the Department of Reinforced Concrete and Masonry Structures, of Tomsk State University of Architecture and Building is working on a method of estimation of reinforced concrete elements using the theory of surfaces of relative resistance regarding strength and crack resistance, based on the deformation model and using real nonlinear diagrams of concrete and reinforcement. The use of the deformation model allows solving problems of this type [11-12]. This method makes it possible to observe strength and crack resistance of standard sections of reinforced concrete elements in the entire range of loadings from the central tension to axial compression. Figure 2a shows the surface of the relative resistance according to strength and crack resistance of sections of reinforced concrete elements, plotted in threedimensional space of coordinates $\alpha_{n}, \alpha_{m x}, \alpha_{m y}$.

Strength conditions of standard section of reinforced concrete elements can be written as: 


$$
\alpha_{n} \leq \alpha_{n b}+\alpha_{n s} ; \alpha_{m x} \leq \alpha_{m b x}+\alpha_{m s x} ; \alpha_{m y} \leq \alpha_{m b y}+\alpha_{m s y},
$$

Where:

$\alpha_{n}=\frac{N(t)}{R_{b d} A}$ - relative operating longitudinal force; $\alpha_{m x}=\frac{M_{x}(t)}{R_{b d} S_{x}}$ - relative operating bending moment in the plane of x; $\alpha_{m y}=\frac{M_{y}(t)}{R_{b d} S_{y}}$ - relative operating bending moment in the plane of y; $\alpha_{\mathrm{nb}}=\xi$ - relative longitudinal force, accepted by concrete cross section; $\alpha_{n s}=\sum_{i=1}^{n} \frac{\sigma_{s i}(t) A_{s i}}{R_{b d} A}$ - relative longitudinal force, accepted by reinforcement cross section; $\alpha_{m b x(y)}=\frac{S_{b x(y)}}{S_{x(y)}}$ - relative bending moments, accepted by concrete cross sections in planes of $\mathrm{x}$ and y; $\alpha_{m s x(y)}=\sum_{i=1}^{n} \frac{\sigma_{s i}(t) A_{s i} y_{s i}}{R_{b d} S_{x(y)}}$ - relative bending moments, accepted by reinforcement cross sections in planes of x and y; $N(t), M_{x}(t), M_{y}(t)$ operating longitudinal force and bending moments in the planes of $\mathrm{x}$ and $\mathrm{y}$, respectively; $R_{b d}$ - design resistance of concrete under static or dynamic loadings; $S_{x(y)}$ - static moments of reinforced concrete cross section; $\mathrm{S}_{\mathrm{bx}(\mathrm{y})}$ - static moments of concrete cross section; $A$ - cross area of concrete; $A_{s i}$ - area of i-th reinforcement bar; $\sigma_{s i}(t)$ - stresses in i-th reinforcement bar; $t$ - time coordinate.

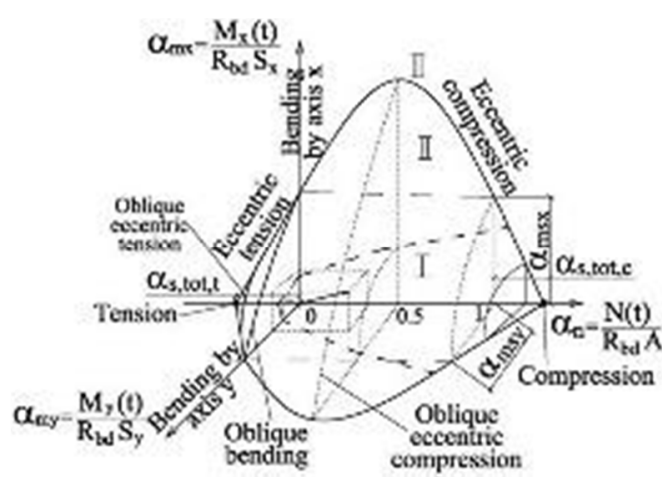

a)

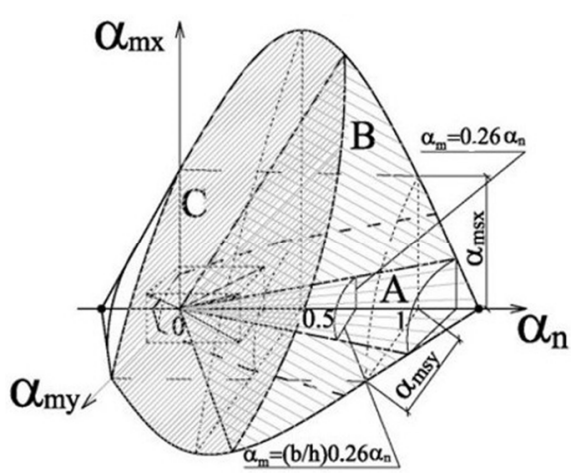

b)

Fig. 2. The surface of the relative resistance of reinforced concrete elements according to the strength: a - stages of the element operation under short-term dynamic loading: I (1a) - element operation in the elastic stage without cracks, II (1b) - element operation in the elastic stage with cracks, III (1c) element operation in the yielded stage, $\mathrm{b}$ - zone of occasional, small and large eccentricities: A - a zone of occasional eccentricities, B - a zone of small eccentricities, C - a zone of large eccentricities.

Ultimate bending moments, accepted by reinforced concrete elements in the planes of $\mathrm{x}$ and $y$, are taken with regards to the gravitational center of concrete section. Bearing capacity of concrete cross section under compression and compression with bending with 
regards to its gravitational center is taken as the parameter items. Dependence between the accepted longitudinal force and bending moment of each plane for elements of a rectangular concrete sections taken in the form of a parabola, and the dependence between the bending moments of the two planes at a fixed longitudinal force is taken in the form of an ellipse. The surface of relative resistance in each plane for reinforced concrete bar elements is approximated by the curve of concrete section strength area, moving on inclined ways, depending on the location of the reinforcement in the section. This surface of relative strength increases at short-term dynamic loading [18], due to the introduction of coefficients of dynamic hardening, depending on the time coordinate, in dependence design.

The surface of relative resistance is divided into three zones, corresponding to the stages of concrete element operation: stage I - elastic stage of crack-free operation, stage II nominally elastic operating stage with cracks, stage III - plastic operating stage, besides that, areas of large, small and accidental eccentricities are differentiated (Fig. 2b).

Calculation method, based on the application of the relative resistance surfaces, allows to extend the issues of forward and reverse engineering of concrete elements of rectangular, circular and annular sections under eccentric short-term dynamic compression, tension and bending.

Good visibility in strength evaluation of reinforced concrete elements is achieved by the vector representation of the relative acting forces arising in the standard sections from the external influences. Thereby, each impact corresponds to components of the vectors of the relative acting forces, and each point of the surface of relative resistance of reinforced concrete elements corresponds to components of resistance vector. The difference between the components of the vectors of relative resistance and relative acting forces is expressed by the components of the vectors of strength reserve of the standard sections of the element. Strength conditions are satisfied at their positive values, bearing capacity of reinforced concrete element is not provided at the negative values. It can be shown graphically in the following way, if the vectors of relative acting forces are inside of the resistance surface, the strength of element is provided, if they go beyond the surface, the bearing capacity of the element is not sufficient.

\section{Experimental research}

Experimental investigation of symmetrically reinforced concrete elements on oblique eccentric short-term dynamic compression, tension and oblique bending was planned and carried out for obtaining background and checking the proposed method of calculation.

\subsection{Experimental program}

Program of experimental studies (Fig. 3) included testing of fifteen concrete specimens of rectangular cross section and fifteen concrete specimens of I-shaped cross-section of two meters in length for short-term dynamic loading. The following specimen designation was accepted: OB - for the oblique bending testing, OEC - for the oblique eccentric compression testing, OET - for oblique eccentric tension testing; the number of letters indicates the serial number of the element, the letter R or I - rectangular or I-shaped crosssection, respectively. 


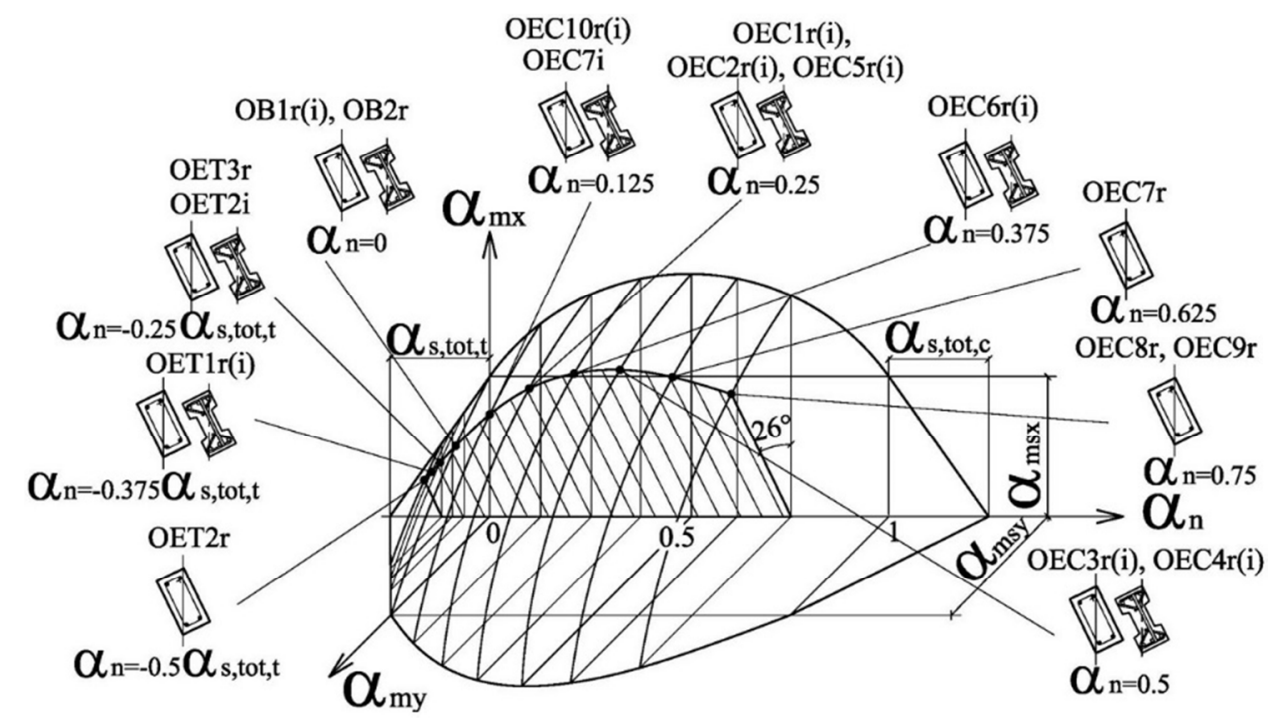

Fig. 3. Program of experimental investigation.

The level of longitudinal force, acting on the specimen, varied in experimental investigation, the impact on the strength of reinforced concrete elements was estimated. The dimensions and construction of the experimental specimens are shown in Figure 4.
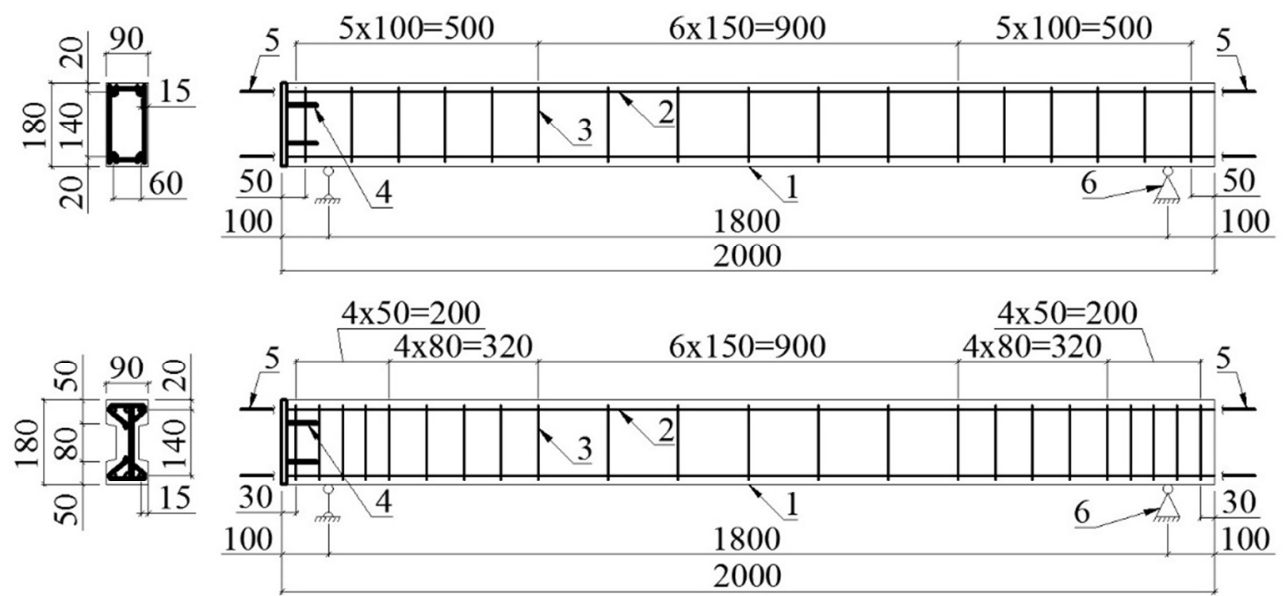

Fig. 4. The dimensions and construction of the experimental rectangular and I-beam cross-section elements. Legend: 1 - specimen, 2 - longitudinal reinforcement of class A-III of $10 \mathrm{~mm}$ diameter, 3 cross reinforcement of class Bp-I of $4 \mathrm{~mm}$ diameter, 4 - concrete insert, 5 - protruding reinforcement, 6 - supporting structure.

\subsection{Experimental equipment}

The basis was taken from existing experimental stands that implement tests by falling cargo (drop-test) [13-15]. Specially designed equipment for experimental investigation of building structures was used for information on the stress-strain state of the elements, which included test stands, made on the basis of pile driver, the measurement information sensing devices (resistive strain sensor, sensors of large displacement, dynamometer etc.), together with measuring systems MIC-300, MIC-400. The operating dynamic loading, support reactions, deflections, acceleration, deformation of concrete and reinforcement 
according to the height ofcross section and length of the element were measured at testing. The special equipment for measuring the supporting dynamic reactions and the method of gluing resistive strain sensors on rebars were used at testing.

\subsection{Test conditions}

Experimental specimen was tested in horizontal position and mounted on special supporting structures at an angle where the force line passed through the corners of the cross-section of the element. Longitudinal loading is applied by means of cuddy and pumping works. Experimental short-term dynamic loading was created by means of the load fall of $400 \mathrm{~kg}$ from the height of $570 \mathrm{~mm}$. Loading duration of action was $25-40 \mathrm{~ms}$, with loads served through rubber edges which increase its operating time.

\section{Results and discussion}

Experimental investigation allowed to obtain curves of concrete and reinforcement strains, deflections of reinforced concrete elements, accelerations, actual loading with time. Such experimental data obtained by other authors, for example.

\subsection{Strains}

Ultimate compressive strains of concrete were $(230-270) \times 10^{-5}$ units of relative length and ultimate stretching strains of reinforcement $-250-300 \times 10^{-5}$ units of relative length (Fig. $5)$.
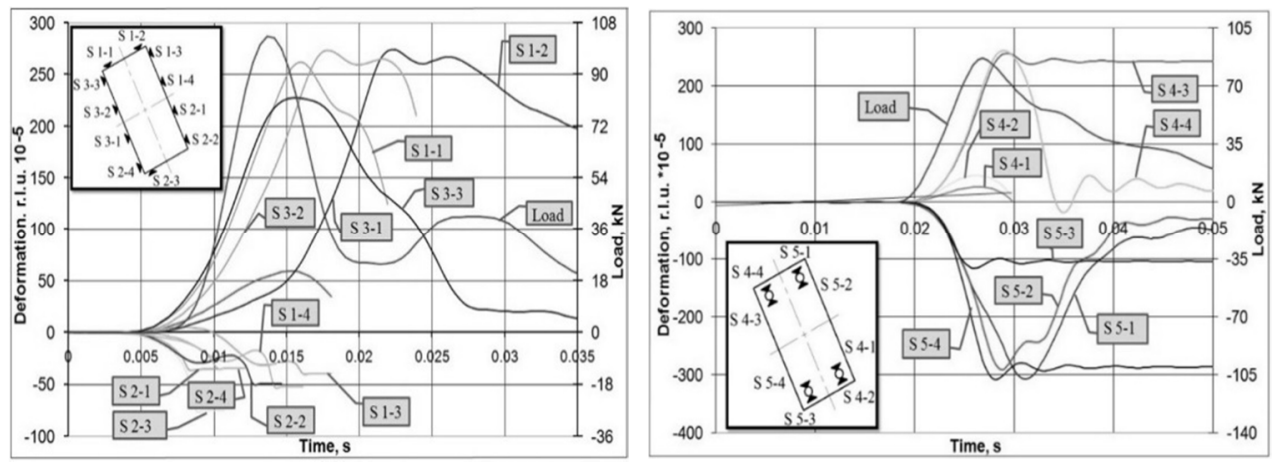

Fig. 5. Typical strain curves of concrete (at the left) and reinforcement (at the right) under short-term dynamic loading, r.l.u. - relative length units.

The delay of concrete strains peak in relation to the loading peak was 4-13 ms, and the delay of reinforcement strains peak in relation to the loading peak was 3-10 ms. The appropriateness of the application of the theory of plane sections atestimation of reinforced concrete elements for oblique eccentric short-term dynamic compression, tension and bending was confirmed (Fig.6). 


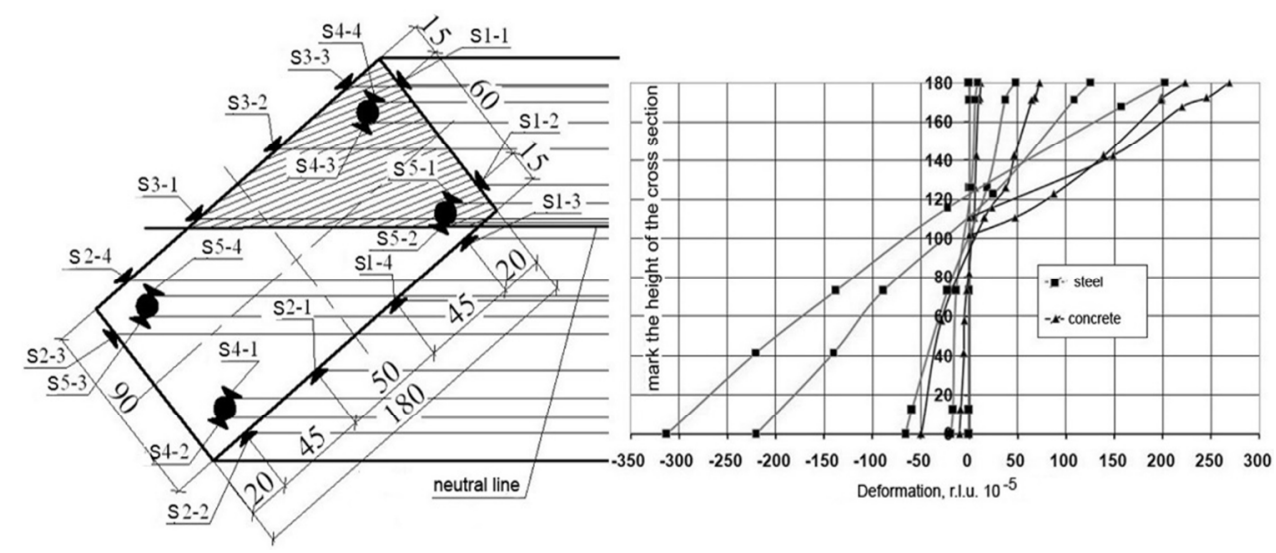

Fig. 6. Typical graph of strain distribution according to the height of the section of the experimental specimen with time.

\subsection{Bearing capacity}

Analysis of the effect of longitudinal force level on bearing capacity of concrete experimental specimens gave the following results. Increasing level of tensile longitudinal force reduces the bearing capacity of the element, as shown by researches, from $56.6 \mathrm{kN}$ at the absence of longitudinal force to $31.7 \mathrm{kN}$ at the level of the longitudinal force equal to $\alpha_{\mathrm{n}}=0.5 \alpha_{\mathrm{s}, \text { tot, } \mathrm{t}}$. Increasing level of longitudinal compressive force gives rise to bearing capacity from $56.6 \mathrm{kN}$ (at the absence of a longitudinal force) to $101.6 \mathrm{kN}$ at the level of the longitudinal force equal to $\alpha_{\mathrm{n}}=0.5$ for rectangular cross section elements. Further increase of the longitudinal force decreases the bearing capacity of the element to $86.6 \mathrm{kN}$ at the compression level equal to $\alpha_{n}=0.75$. It can be concluded that the increase of the level of concrete specimens compression to a value of about $\alpha_{n}=0.5$ has positive effect on its bearing capacity under short-term dynamic loading (Fig. 7).

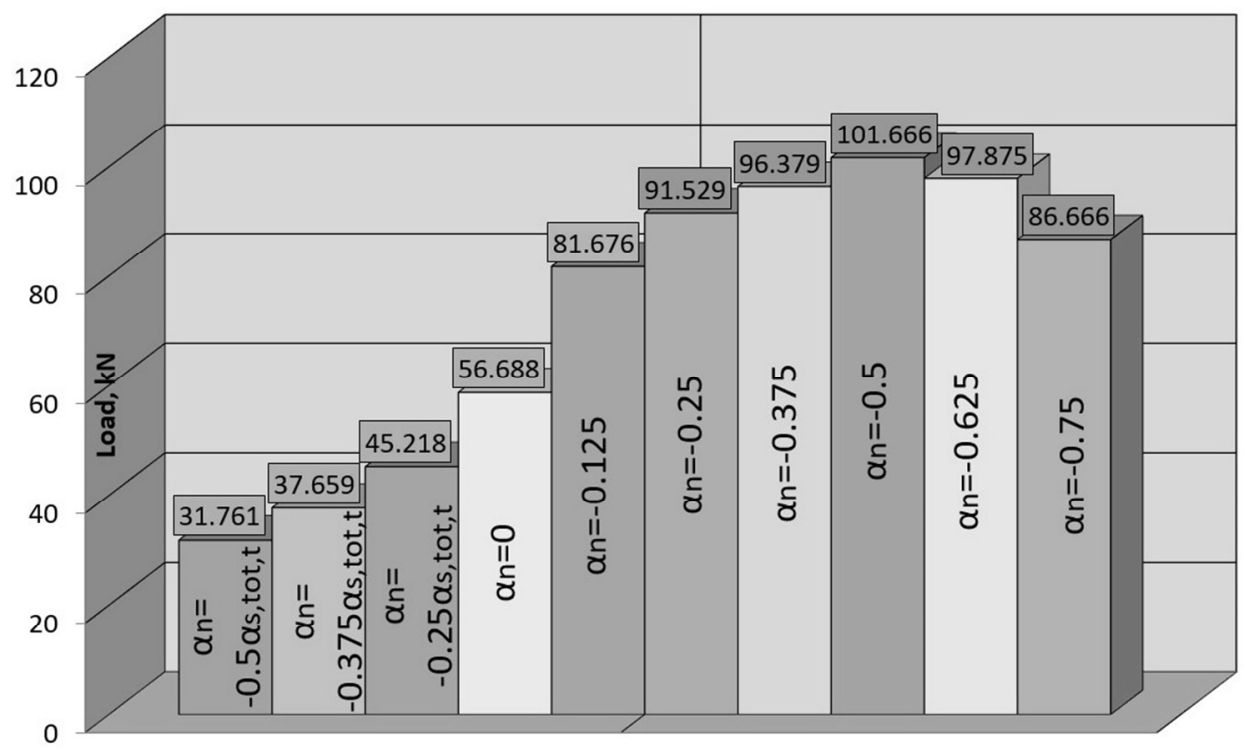

Fig. 7. The diagram of the bearing capacity of reinforced concrete specimens of rectangular crosssection, according to the level of the longitudinal force. 


\subsection{Deformation}

The maximum deflections occurred at the minimum longitudinal force, the increase in the level of the longitudinal force deflections decreased at the increase of the longitudinal force level. The maximum deflection value ranged from 50 to $90 \mathrm{~mm}$ for various experimental specimens (Fig. 8).

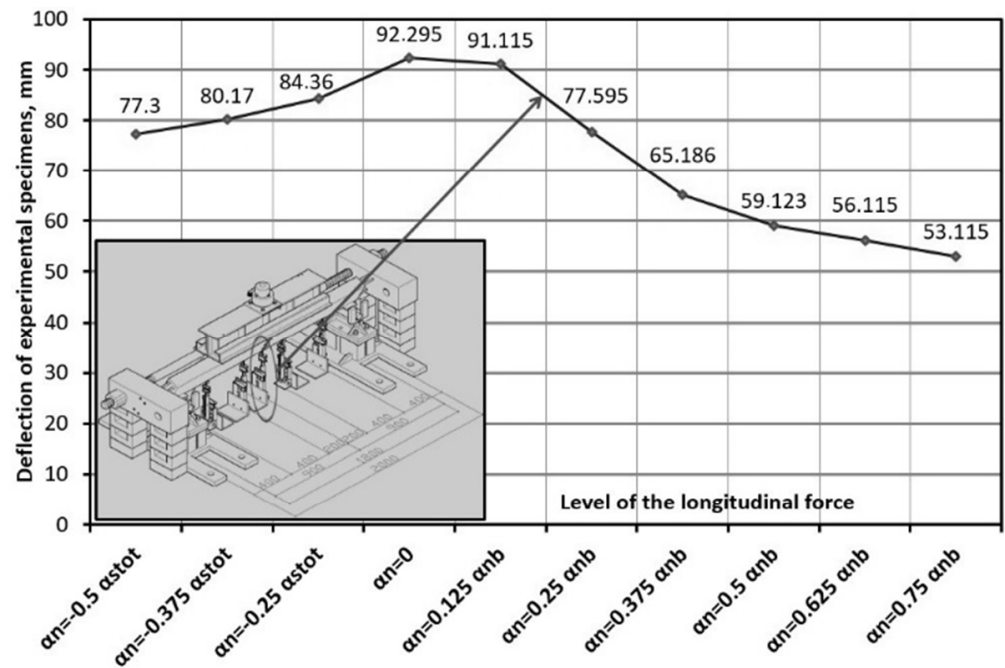

Fig. 8. Deflection curves of the experimental specimens of rectangular cross-section, depending on the level of the longitudinal force.

\subsection{Accelerations}

In addition, the values of concrete specimens accelerations at specific points according to the length of the beams were obtained. Acceleration at the mid-span of experimental specimens averaged $400 \mathrm{~m} / \mathrm{s}^{2}$. The typical graph of acceleration in the mid-span of the concrete specimen is shown in Figure 9. The acceleration filtering was conducted at the natural vibration frequency of the beam, which was $70 \mathrm{~Hz}$, under analysis of experimental data. The natural vibration frequency of the beam was determined as follows. Vibrator with vibration frequency adjustability was installed in the mid-span, and acceleration indicator was mounted to the beam at various points, which showed accelerations of the beam in real time. With increasing the vibration frequency to a certain level, the system was in resonance - this frequency was taken as the natural vibration frequency of the beam. 


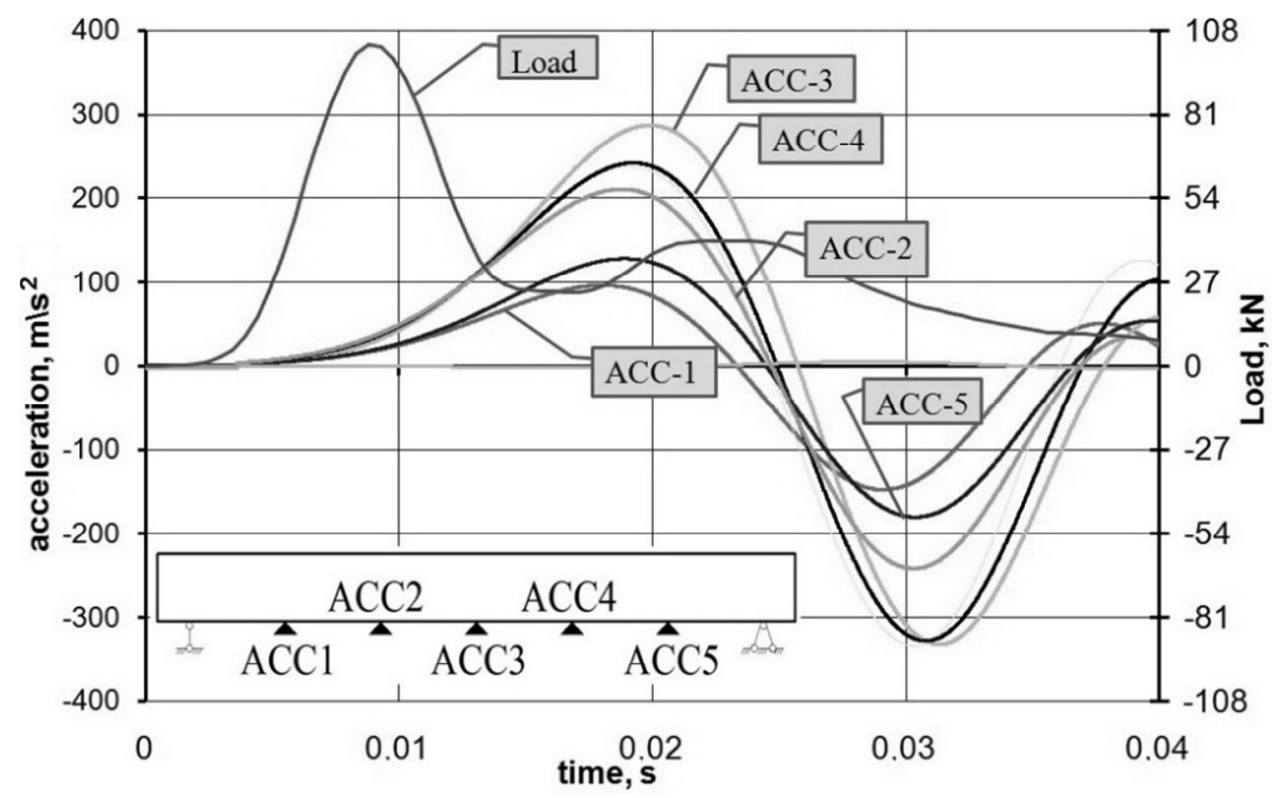

Fig. 9. Typical graph of accelerations of concrete specimen, ACC - accelerometer.

\subsection{Scheme of failure}

The effect of the longitudinal force level on the scheme of failure of the experimental specimens was estimated (Fig. 10).

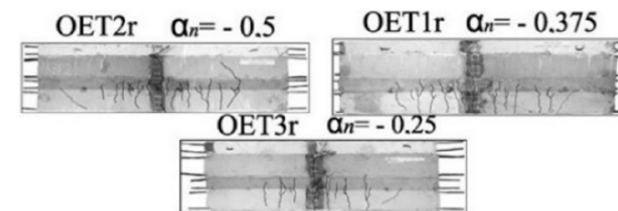

a)

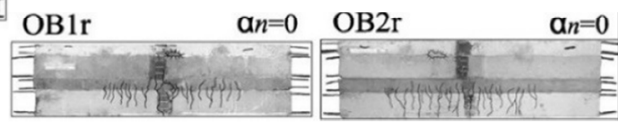

b)

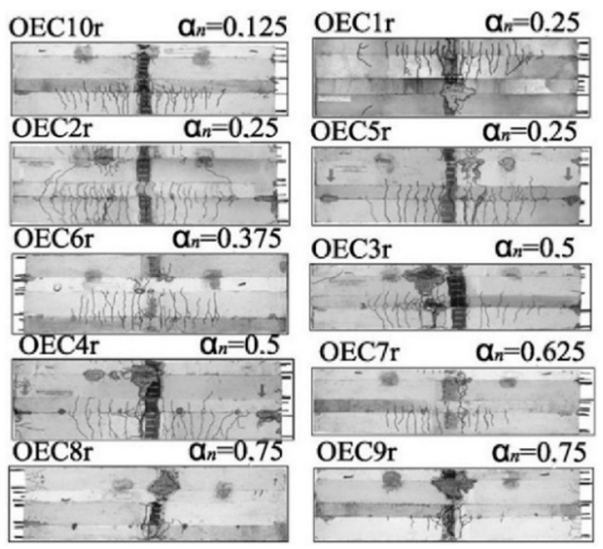

c)

Fig. 10. The rectangular elements failure under short-term dynamic loading, depending on the longitudinal force level (developed views): $\mathrm{a}$ - under oblique eccentric tension, $\mathrm{b}$ - under oblique bending, $\mathrm{c}$ - under oblique eccentric compression. 
Figure 11 shows the overall view of the failure of the experimental concrete beams, depending on the longitudinal compressive or tensile forces. The formation of through wall crack along the specimen perimeter in the central cross section of the element is observed under testing for oblique eccentric tension with high level of longitudinal tensile force. Compressed zone is not destroyed. The amount of normal cracks increases and the central crack decreases at the decreasing of the tensile force value, while there is the failure of the compressed zone of concrete. The formation of several cracks, normal to the longitudinal axis of the element in the area of pure bending, is observed at low level of longitudinal compressive force. The number of cracks reduces and the failure is concentrated on the compressed zone of concrete under increase in compression level.

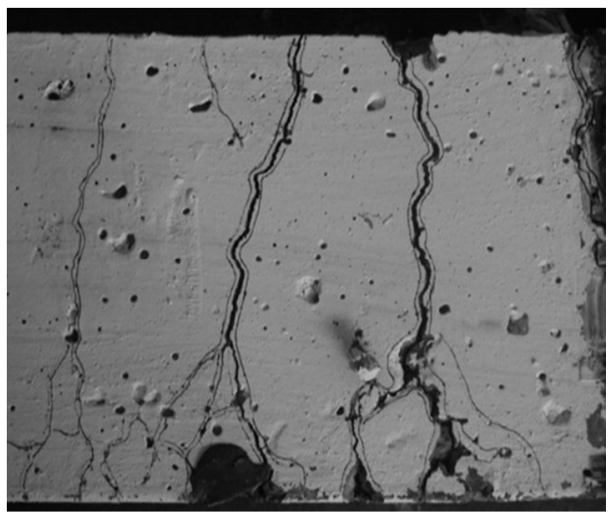

a)

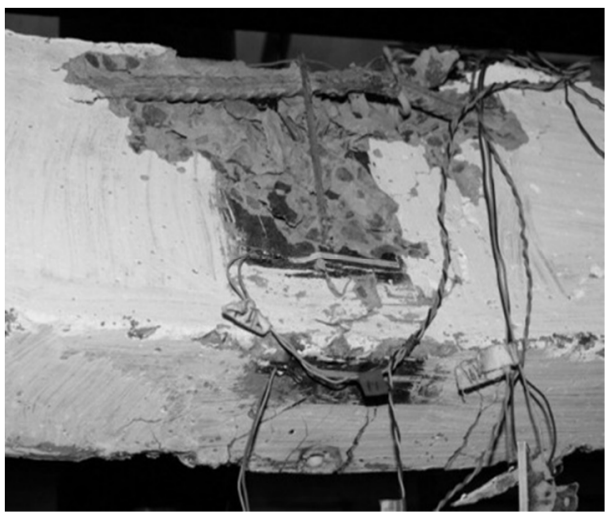

b)

Fig. 11. The experimental specimens failure: $a$ - at high level of longitudinal tensile force; $b$ - at high level of compressive longitudinal force.

\section{Conclusions}

Based on the experimental results it can be concluded that the method described can be effectively used for the calculation of reinforced concrete elements under static and dynamic oblique eccentric loadings.

New data about strength and deformation of symmetrically reinforced concrete elements on oblique eccentric short-term dynamic compression, tension and oblique bending under dynamic loading were obtained.

Comparison of the experimental investigation results and theoretical calculations, which were carried out, using the theory of surfaces of relative resistance according to strength, gave satisfactory respond, the disagreements did not exceed $15-20 \%$.

The developed method is brought to the program product, allowing to estimate the reinforced concrete elements of rectangular cross section on static and short-term dynamic loading at any combination of longitudinal forces and bending moments of two planes.

The article is supported by the grand of the Russian Foundation for Basic Research, project № 18-47$860015 \backslash 19$. Mathematical simulation of mechanical properties of constructions made of fibre concrete with metallic and nonmetallic fillers was carried out with the use of the super computer and additive technologies. 


\section{References}

1. C. Albertini, E. Cardoni, K. Labibes, Experimental Mechanics 39, 137-141 (1999) DOI 10.1007/BF02331117

2. Y. Chen, I.M. Maw, Proceedings of the ICE - Structures and Buildings 162(1), 45-56 (2009) DOI 10.1680/stbu.2009.162.1.45

3. G.I. Odnokopylov, D.Yu. Sarkisov, E.A. Butuzov, Bulletin of the Tomsk Polytechnic University. Geo Assets Engineering 329(12), 122-135 (2018) DOI: $10.18799 / 24131830 / 2018 / 12 / 28$

4. A.S. Savinykh, G.V. Garkushin, S.V. Razorenov, G.I. Kanel, International Journal of Fracture 209, 109-115 (2017) DOI 10.1007/s10704-017-0244-9

5. X. Chen, C. Chen, L. Xu, Y. Shao, Magazine of Concrete Research 69(3), 109-119 (2017) DOI 10.1680/jmacr.15.00548

6. B. Chiaia, O. Kumpyak, L. Placidi, V.B. Maksimov, Engineering Structures 96, 88-99 (2015) DOI 10.1016/ j.engstruct.2015.03.054

7. Z.R. Galyautdinov, AIP Conference Proc. Youth, Science, Solutions: Ideas and Prospects Tomsk, 40-44 (2019) DOI 10.1063/1.4973043

8. G.L. Golewsski, Composite Structures 223(1), 110939 (2019) DOI 10.1016/j.compstruct.2019.110939

9. H. Li, W. Chen, H. Hao, Engineering Structures 1911(5), 247-263 (2019) DOI 10.1016/j.engstruct.2019.04.051

10. H. Sadraie, A. Khaloo, H. Soltani, Engineering Structures 1911(5), 62-81 (2019) DOI 10.1016/j.engstruct.2019.04.038

11. V. Filatov, A. Suvorov, Procedia Engineering 153, 144-150 (2016) DOI 10.1016/j.proeng.2016.08.094

12. D.A. Panfilov, A.A. Pischulev, V.V. Romanchkov, Procedia Engineering 153, 531-536 (2016) DOI 10.1016/j.proeng.2016.08.183

13. A.S. Agar Ozbek, J. Weerheijm, E. Schlangen, K. van Breugel, Cement and Concrete Composites 39 (2013) DOI 10/1016/j.cemconcomp.2013.03.012

14. W. Zhang, S. Chen, Y. Liu, Construction and Building Materials 140(1), 31-35 (2017) DOI 10/1016/j.conbuildmat.2017.02.098

15. M. Wu, Z. Chen, C. Zhang, Engineering Fracture Mechanics 13(5), 94-112 (2015) DOI 10.1016/j.engfracmech.2014.12.019 